\title{
Physical Activity Enhances Metabolic Fitness Independently of Cardiorespiratory Fitness in Marathon Runners
}

\author{
M. J. Laye, ${ }^{1,2}$ M. B. Nielsen, ${ }^{1}$ L. S. Hansen, ${ }^{1}$ T. Knudsen, ${ }^{1}$ and B. K. Pedersen ${ }^{1}$ \\ ${ }^{1}$ Centre of Inflammation and Metabolism, Rigshospitalet, Department of Biomedical Sciences, University of Copenhagen, \\ 2200 Copenhagen, Denmark \\ ${ }^{2}$ The Buck Center for Research on Aging, Novato, CA 94945, USA
}

Correspondence should be addressed to M. J. Laye; mjlaye@gmail.com

Received 3 February 2015; Accepted 12 February 2015

Academic Editor: Francisco Blanco-Vaca

Copyright (C) 2015 M. J. Laye et al. This is an open access article distributed under the Creative Commons Attribution License, which permits unrestricted use, distribution, and reproduction in any medium, provided the original work is properly cited.

\begin{abstract}
High levels of cardiovascular fitness (CRF) and physical activity (PA) are associated with decreased mortality and risk to develop metabolic diseases. The independent contributions of CRF and PA to metabolic disease risk factors are unknown. We tested the hypothesis that runners who run consistently $>50 \mathrm{~km} / \mathrm{wk}$ and/or $>2$ marathons/yr for the last 5 years have superior metabolic fitness compared to matched sedentary subjects (CRF, age, gender, and BMI). Case-control recruitment of 31 pairs of runner-sedentary subjects identified 10 matched pairs with similar $\mathrm{VO}_{2 \max }(\mathrm{mL} / \mathrm{min} / \mathrm{kg})\left(\right.$ similar- $\left.-\mathrm{VO}_{2 \max }\right)$. The similar- $\mathrm{VO}_{2 \max }$ group was compared with a group of age, gender, and $\mathrm{BMI}$ matched pairs who had the largest difference in $\mathrm{VO}_{2 \max }$ (different- $\mathrm{VO}_{2 \max }$ ). Primary outcomes that defined metabolic fitness including insulin response to an oral glucose tolerance test, fasting lipids, and fasting insulin were superior in runners versus sedentary controls despite similar $\mathrm{VO}_{2 \max }$. Furthermore, performance (velocity at $\mathrm{VO}_{2 \max }$, running economy), improved exercise metabolism (lactate threshold), and skeletal muscle levels of mitochondrial proteins were superior in runners versus sedentary controls with similar $\mathrm{VO}_{2 \max }$. In conclusion subjects with a high amount of PA have more positive metabolic health parameters independent of CRF. PA is thus a good marker against metabolic diseases.
\end{abstract}

\section{Introduction}

High levels of physical activity (PA) and cardiorespiratory fitness (CRF) are independently associated with a low risk for many chronic diseases [1] and mortality [2]. While related, the distinction between these CRF and PA is critical. CRF integrates many different physiological systems into a single measure of function. On the other hand PA is comprised of any body movements, which may not necessarily lead to improvements in CRF. However, in general metareviews and independent studies indicate that the protective effect of CRF is greater when compared to PA, in most [3-5], but not all cases [6]. One factor in the discrepancy between the relative health effects for CRF versus PA is the level of precision in measurements of CRF versus PA. Assessment of CRF in large epidemiological studies is typically assessed by a treadmill or ergometer test [3], while PA is assessed by a questionnaire [7]. Indeed, the correlation between reported PA using the international physical activity questionnaire and
CRF as measured by a treadmill test ranged from 0.24 to 0.32 in 3 reviewed studies [8]. Furthermore, the range and types of PA vary dramatically, while CRF consists of a single well characterized number.

CRF is a powerful predictor of early mortality independent of PA levels, BMI, or other risk factors $[9,10]$. CRF also varies largely within sedentary populations [11]. For instance in a population of 1707 men aged 20-49 the difference between 20th and 80th percentile is more than $30 \%(36.8-48.5 \mathrm{~mL} / \mathrm{kg} / \mathrm{min})$ [11]. Likewise the change in CRF to a standardized exercise training program varies largely from $-4.7 \%$ to +58.0 [12]. While large cross-sectional studies suggest higher CRF are associated with lower levels in biomarkers for metabolic disease other intervention studies show that improvements in CRF are only weakly correlated with improved biomarkers [13].

$\mathrm{VO}_{2 \max }$ in sedentary population of monozygotic twins is highly heritable (77\%) even with correction for various 
anthropometric measures [14]. Similarly, gains in CRF following 20 weeks of endurance exercise training ( $3 \mathrm{~d} / \mathrm{wk}$ at $55-$ $\left.75 \% \mathrm{VO}_{2 \max }\right)$ are heritable $(47 \%)$ and highly variable, with some individuals showing no response in $\mathrm{VO}_{2 \max }$ [15]. The variability of the response to endurance training is in part explained by differences in age, sex, race, and initial $\mathrm{VO}_{2 \max }$ $[12,16,17]$, an explanation that is not universally found or contributes in totality to the variation of gains in CRF [18].

On the other hand changes in PA can be accomplished through behavioural strategies that are not subject to the same variability that CRF is. Furthermore levels of PA are associated with changes in disease risk. In general, results from the Aerobics Center Longitudinal Study suggest that within groups of individuals who have similar CRF, overall health (cardiovascular health and cancer) is better in individuals with higher PA [6]. One specific example is that PA, independent of CRF, is atheroprotective by improving lipoprotein subclass distribution, postprandial lipoprotein metabolism, inflammation, and endothelial function [19-23]. Conversely, physical inactivity increases the relative risk for at least 35 pathological and clinical conditions [1]. Remarkably, physical inactivity as defined by sitting time is a risk factor for premature death, a number of chronic diseases and pathologies [24]. For example, 20 days of bed rest [25] or 14 days of reduced step count (and thus increased sitting) [26] reduce CRF $27 \%$ and $7 \%$, respectively. However, it remains difficult to isolate the independent roles of PA, inactivity, and CRF in health parameters as most studies are not designed to explicitly control for CRF, while changing just PA.

In the present study, we hypothesized that PA would improve metabolic fitness independent of CRF. We therefore sought to identify two groups of people who were closely matched with regard to age, gender, and CRF, but who differed markedly with regard to their PA level. We recruited an endurance-trained group (consisting of recreational marathon runners) and a control group, matched for BMI, age, and gender, and tested various metabolic health parameters (blood lipids, glucose tolerance, and body composition) as our primary outcome. The endurance group fulfilled at least one of two inclusion criteria: (1) they had had an average training volume of at least 50 kilometers per a week for at least the past 5 years or (2) they completed at least 10 marathons within the past 5 years including 2 within the last 14 months. Because of the known variability in CRF it was our aim to compare a subgroup (runners versus controls) with similar- $-\mathrm{VO}_{2 \max }$ (similar- $-\mathrm{VO}_{2 \max }$ ) and a subgroup (runners versus controls) with different- $\mathrm{VO}_{2 \max }$ (different- $\mathrm{VO}_{2 \max }$ ).

\section{Methods}

2.1. Recruitment of Subjects. Subjects were recruited through newspaper adverts and emails listserves in 2008-2009 from the greater Copenhagen metro area. Marathon runners fulfilled at least one of two inclusion criteria: (1) having an average training volume of at least 50 kilometers per week for at least the past 5 years, as determined by questionnaire or (2) having ran at least 10 marathons in the past 5 years including 2 within the last 14 months. After a marathon runner had completed the physiological testing a sedentary subject was recruited to match the BMI, age, and sex of the marathon runner. Sedentary subjects were limited to individuals who did not obtain more than 1 hour of structured exercise per week. Exclusion criteria prior to inclusion in the study for both groups included chronic diseases, pregnancy within the last 3 months, abuse of alcohol, use of cigarettes, or use of performance enhancing drugs. In total, 31 pairs of subjects were recruited. No subjects were excluded after testing. The purpose of the study, possible risks, and discomforts were explained to the subjects before written consent was obtained. The study was approved by the Local Ethical Committee of Copenhagen and Frederiksberg and was in accordance with the Declaration of Helsinki.

Subjects underwent two days of testing. On day 1 , subjects arrived to the lab in a fasted condition and underwent a physical examination during which blood pressure, resting heart rate (HR), and blood were taken for standard laboratory measurements including blood lipids.

Following the examination subjects underwent a muscle biopsy. Briefly, muscle biopsies from vastus lateralis were obtained at rest using the percutaneous Bergstrom needle method with suction under local anaesthesia, using 3-5 mL of $20 \mathrm{mg} \mathrm{mL}^{-1}$ lidocaine (SAD, Denmark Copenhagen). Muscle tissue was immediately frozen in liquid nitrogen and stored at $-80^{\circ} \mathrm{C}$ until further analysis. Following the muscle biopsy, subjects underwent a dual-energy X-ray absorptiometry (DEXA) measurement and an oral glucose tolerance test, which was administered at 10:00 AM.

2.2. Separation of Subjects into "Similar-VO $\mathrm{O}_{2 \max }$ " and "Different- $V O_{2 \max }$ ". After all subjects had undergone the standard testing, each runner-sedentary pair of subjects was ranked by their relative difference in $\mathrm{VO}_{2 \max }(\mathrm{mL} / \mathrm{kg} / \mathrm{min})$. Runners $\mathrm{VO}_{2 \max }$ ranged from $-5 \%$ to $64 \%$ higher than their sedentary pair. We separated the cohort into thirds and focused our analysis on the 10 pairs of marathon runner and sedentary controls with closest $\mathrm{VO}_{2 \max }(-5 \%$ to $15 \%$, mean $5 \%$ higher, and absolute difference $2.2 \mathrm{~mL} / \mathrm{kg} / \mathrm{min}$ ) and the 10 pairs with the largest difference in $\mathrm{VO}_{2 \max }$ (27\% to $64 \%$, mean of $44 \%$ high, and absolute difference $17.3 \mathrm{~mL} / \mathrm{kg} / \mathrm{min}$ ). We refer to these two groups as similar- $\mathrm{VO}_{2 \max }$ and different $-\mathrm{VO}_{2 \max }$, respectively.

2.3. Body Composition. Whole body fat and fat-free tissue mass measurements were performed using a dual-energy X-ray absorptiometry (DXA) scanner (Lunar Prodigy, GE Healthcare, WI, Madison USA, software v. 8.8).

2.4. Oral Glucose Tolerance Test. Subjects underwent a threehour oral glucose tolerance test (OGTT). Within 2 minutes, the subject ingested a drink containing 75 g glucose (Dextrose Anhydre, Roquette Freres, France) dissolved in $300 \mathrm{~mL}$ of water. Venous blood samples were collected from an antecubital venous catheter before and 10, 20, 30, 60, 90, 120, 150, and 180 minutes after ingestion of the solution. Blood was drawn into tubes (Vacuette, Serum clot activator and Sodium Fluoride/Potassium Oxalate, Hettich, Labinstruments APS) for determination of glucose and insulin to each time point. 
Blood samples were analyzed for standard biochemical measurements by the biochemical department of Rigshospitalet.

2.5. Exercise Testing. The treadmill (Runrace, Technogym, Italy) test consisted of a lactate threshold and maximal oxygen consumption $\left(\mathrm{VO}_{2 \max }\right)$ portion, which took less than 20 minutes. Indirect calorimetry measurements were collected throughout the test (Quark b2, CosMed, Rome, Italy). For marathon runners the test began at $3 \mathrm{~km} \cdot \mathrm{h}^{-1}$ slower than their current marathon pace. The controls started at $6-7 \mathrm{~km} \cdot \mathrm{h}^{-1}$. Every third minute we increased the speed $1 \mathrm{~km} \cdot \mathrm{h}^{-1}$, the third minute of which $\mathrm{VO}_{2}$ was averaged until lactate threshold was reached. After each stage subjects stepped off the treadmill for the $15 \mathrm{~s}$ required to obtain a blood sample, after which they began the next stage while the measurement was conducted. Blood samples were collected within $15 \mathrm{sec}$ of the end of the stage by wiping sweat, ethanol cleaning, and drying of a nonlanced finger. Lactate was measured by a handhold lactate device (Lactate Scout, EKF Senslab GmbH, Leipzig, Germany), which requires $0.5 \mu \mathrm{L}$ whole blood and 10 seconds for a measurement. The workload at which the concentration of blood lactate reached $4.0 \mathrm{mmol} / \mathrm{mL}$ or began to increase exponentially was selected as lactate threshold. We performed posttest analysis to ensure that the stage at which lactate threshold was reached showed agreement with the ventilatory threshold.

Without a rest subjects began the $\mathrm{VO}_{2 \max }$ test at the speed lactate threshold was reached. The speed was increased $1 \mathrm{~km} \cdot \mathrm{h}^{-1}$ every minute until the participant was unable to keep up with speed and/or increasing the workload no longer increased $\mathrm{VO}_{2}(\mathrm{~mL} / \mathrm{L})$. All subjects reached exhaustion or plateaued $\mathrm{VO}_{2 \max }$ and had an RER $>1.10$. Heart rate was recorded during the whole test.

2.6. Immunoblotting. Immunoblots were completed as previously reported [27]. Briefly, skeletal muscle biopsies were weighed and homogenized using a Tissuelyser (Qiagen) (50 mM Tris. $\mathrm{HCl}, 150 \mathrm{mM} \mathrm{NaCl}, 1 \mathrm{mM}$ EDTA, 1 mM EGTA, $50 \mathrm{mM} \mathrm{NaF}, 5 \mathrm{mM} \mathrm{NaP}$, and $0.2 \%$ Ipegal-CA-630) supplemented with complete protease inhibitor cocktail (Roche) and phosphatase inhibitors (Sigma). Protein concentrations were measured with the Bradford assay [28]. Equal amounts of proteins were subjected to SDS-PAGE using Invitrogen 8\% precast gels and an I-blot dry transfer machine according to the manufacturer's instructions. Each GEL contained either the different- $\mathrm{VO}_{2 \max }$ group or the similar- $\mathrm{VO}_{2 \max }$ group with pairs loaded in adjacent lanes. $30 \mu \mathrm{g}$ of protein was loaded in each well. Polyvinylidene fluoride membranes were probed with primary antibodies at the following concentrations: MnSOD (\#06-984; Upstate) 1:2000, GPX1 (number 3206; Cell Signaling) 1:5000, HSP72 (SPA-810F; Gentaur) 1:1000, COXIV-3E11 (number 4850; Cell Signaling) 1:2000, GLUT4 (PA1-1065; Thermo Fischer) 1:1000, VEGF (sc-152; Santa Cruz) 1:500, and MHCIIa (number 3403; Cell Signaling) Detection of primary antibodies was performed using either a mouse (Pierce) or rabbit (Dako) peroxidase-conjugated IgG, and protein signals were visualized using FEMTO-enhanced chemiluminescence and a Bio-Rad Chemidoc XRS imager.
Equal protein loading and transfer was verified by betatubulin signal and total lane reactive brown signal, which stains for total protein. Quantification of the immunoblots was done using Image J (National Institutes of Health, Bethesda, MD, http://rsb.info.nih.gov/ij/) and corrected for total signal on each blot to correct across blots.

2.7. Statistics. All statistics were performed in Graph Pad (version 5.00 for Windows, GraphPad Software, San Diego, California, USA, http://www.graphpad.com/). Unless noted in the text, a two-way ANOVA with marathon runner/control and similar $-\mathrm{VO}_{2 \max } /$ different $-\mathrm{VO}_{2 \max }$ as the two factors was performed. If either factor showed significance post hoc analysis was done by Bonferroni correction with significance set at $P<0.05$.

\section{Results}

3.1. Matching of Healthy Controls and Marathon Runners. A total of 40 subjects, 20 runners, and 20 sedentary runners were included for analysis to take advantage of similarities or differences in $\mathrm{VO}_{2 \max }$. The subjects were further divided into similar- $\mathrm{VO}_{2 \max }(n=10$ for runners and sedentary) and different- $\mathrm{VO}_{2 \max }(n=10$ for runners and sedentary). Basic anthropometrics can be found in Table 1, indicating that the experimental design resulted in well matched subjects by age ( $P=0.97$ for interaction) and body weight $(P=$ 0.76 for interaction). The similar- $\mathrm{VO}_{2 \max }$ group runners and sedentary subjects had similar body fat percentages ( $t$-test), while the different- $\mathrm{VO}_{2 \max }$ group runners had significantly lower body fat than the sedentary group.

3.2. Separation of Paired Subjects Based on Their $V O_{2 \max }$ Similarity. As expected runners as a group had a higher $\mathrm{VO}_{2 \max }$ than healthy controls (Figure $1, P<0.0001$ ). In ranking $\mathrm{VO}_{2 \max }$ difference between one marathon runners and one sedentary subject the 31 differences ranged from $-5 \%$ to $64 \%$, with one-third of the pairs showing a $10 \%$ or less difference in $\mathrm{VO}_{2 \max }$. In this subgroup, which we call similar- $\mathrm{VO}_{2 \max }$, runners had on average only a $5.2 \%$ higher $\mathrm{VO}_{2 \max }$ (range of $-5 \%$ to $15 \%$ for runners/controls, Figure 1, $P=0.22$ by $t$-test). The similar- $\mathrm{VO}_{2 \max }$ group allowed us to compare a group of individuals with the same CRF, but different levels of PA. At the other extreme in the 10 pairs of subjects with the largest difference in $\mathrm{VO}_{2 \max }$, which we call different- $\mathrm{VO}_{2 \max }$, runners had on average a $43 \%$ higher $\mathrm{VO}_{2 \max }$ (range of 27\%-64\% higher, Figure 1, $P<0.001$ ). The different- $\mathrm{VO}_{2 \max }$ subgroup allowed us to examine the degree and magnitude to which high CRF and high PA were associated with better metabolic health.

3.3. Runners Metabolic Profile Was Improved Relative to Healthy Controls. To assess the overall metabolic health of the subjects, blood lipids and oral glucose tolerance tests were conducted. Fasting levels of insulin, total cholesterol, LDL, and triglycerides were all significantly lower, and HDL was significantly higher in the runners versus controls (Table 1). Similarly, the insulin response during an OGTT was 


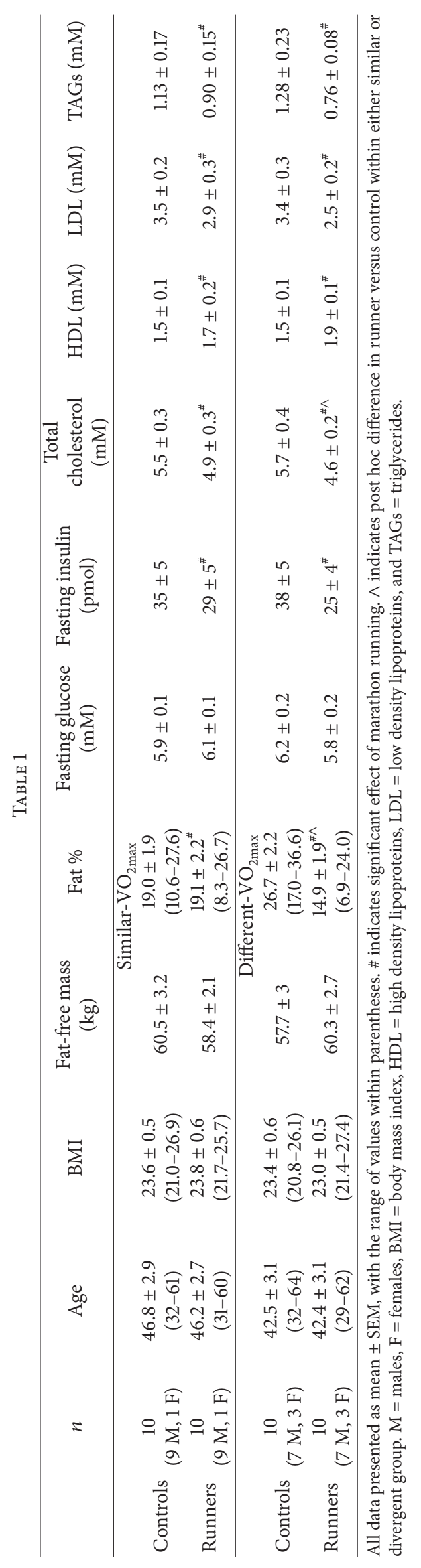




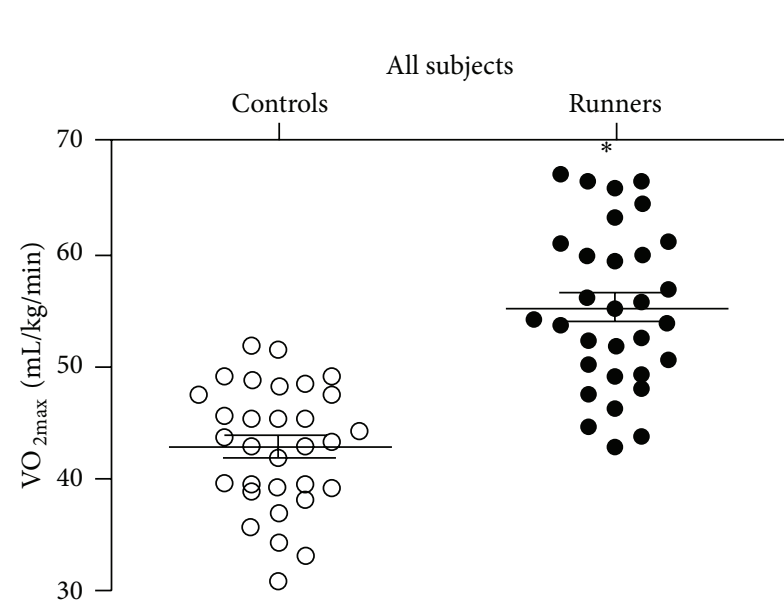

(a)

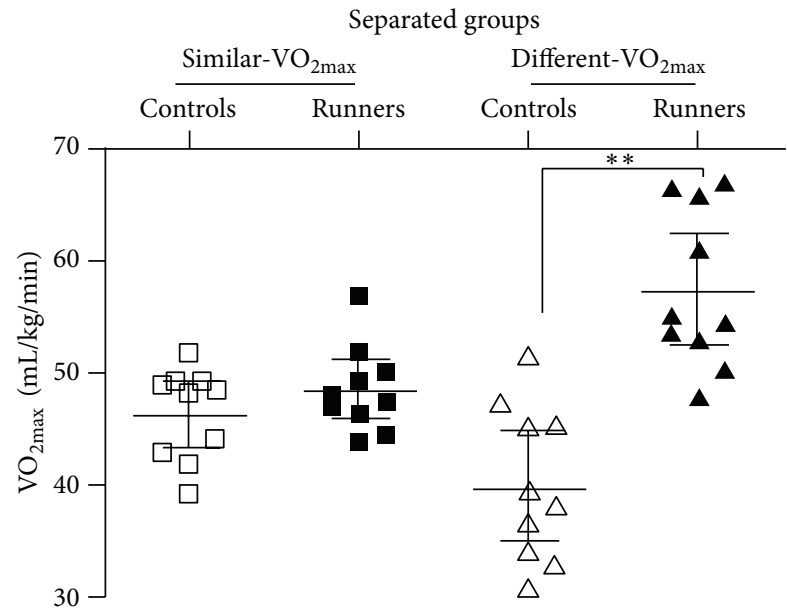

(b)

FIGURE 1: $\mathrm{VO}_{2 \max }(\mathrm{mL} / \mathrm{kg} / \mathrm{min})$ was determined in marathon runners and controls who were individually matched for age, BMI, and gender with one runner. Runners as a group had a significantly higher $\mathrm{VO}_{2 \max }$ than their sedentary paired control (Panel (a)) ( $n=31 /$ group, $P<$ $0.0001, t$-test). When we stratified the pairs by difference in $\mathrm{VO}_{2 \max }$ between each runner and their control the 10 pairs with the most similar$\mathrm{VO}_{2 \max }$ did not significantly differ in $\mathrm{VO}_{2 \max }$ (Panel (b)) $\left(n=10, P=0.22\right.$, $t$-test). In 10 pairs with the most different-VO $\mathrm{V}_{2 \max }$ the runners had a significantly higher $\mathrm{VO}_{2 \max }(n=10, P<0.0001, t$-test $)$.

TABLE 2

\begin{tabular}{|c|c|c|c|c|c|c|c|}
\hline & $\begin{array}{c}\mathrm{VO}_{2 \max } \\
(\mathrm{mL} / \mathrm{kg} / \mathrm{min})\end{array}$ & $\begin{array}{c}\mathrm{VO}_{2 \max } \\
(\mathrm{mL} / \mathrm{kg} \mathrm{FFM} / \mathrm{min})\end{array}$ & $\begin{array}{l}\text { Predicted } \\
\mathrm{VO}_{2 \max }\end{array}$ & $\begin{array}{c}v \mathrm{VO}_{2 \max } \\
(\mathrm{k} / \mathrm{h})\end{array}$ & $\begin{array}{c}\text { Lactate } \\
\text { threshold }(\mathrm{k} / \mathrm{h})\end{array}$ & $\begin{array}{c}\mathrm{RE} \\
\left(\mathrm{mL} \mathrm{O}_{2} / \mathrm{kg} / \mathrm{km}\right)\end{array}$ & $\begin{array}{l}\text { Resting HR } \\
(\mathrm{bpm})\end{array}$ \\
\hline \multicolumn{8}{|c|}{ Similar- $\mathrm{VO}_{2 \max }$} \\
\hline Controls & $46.3 \pm 1.6$ & $58.2 \pm 1.6$ & $39.2 \pm 2.4$ & $13.2 \pm 0.6$ & $10.1 \pm 0.5$ & $234.2 \pm 6.9$ & $58 \pm 2$ \\
\hline Runners & $48.5 \pm 1.2^{\#}$ & $62.5 \pm 1.4^{\#}$ & $51.6 \pm 4.4^{\# \wedge}$ & $15.7 \pm 0.5^{\# \wedge}$ & $13.0 \pm 0.6^{\# \wedge}$ & $205.7 \pm 8.8^{\# \wedge}$ & $50 \pm 3^{\#}$ \\
\hline \multicolumn{8}{|c|}{ Different- $\mathrm{VO}_{2 \max }$} \\
\hline Controls & $40.2 \pm 2.2$ & $54.2 \pm 1.8$ & $36.9 \pm 3.5$ & $11.8 \pm 0.6$ & $8.2 \pm 0.5$ & $224.4 \pm 3.5$ & $59 \pm 3$ \\
\hline Runners & $57.5 \pm 2.2^{\# \wedge}$ & $69.9 \pm 2.2^{\# \wedge}$ & $57.3 \pm 4.0^{\# \wedge}$ & $17.2 \pm 0.9^{\# \wedge}$ & $14.5 \pm 0.5^{\# \wedge}$ & $210.8 \pm 5.1^{\# \wedge}$ & $47 \pm 3^{\# \wedge}$ \\
\hline
\end{tabular}

All data presented as mean \pm SEM. \# indicates significant effect of marathon running. $\wedge$ indicates post hoc difference in runner versus control within either similar or divergent group. $\mathrm{VO}_{2 \max }=$ ventilation of maximum oxygen consumption, $\mathrm{FFM}=$ fat-free mass, $v \mathrm{VO}_{2 \max }=$ velocity at $\mathrm{VO}_{2 \text { max }}, \mathrm{k} / \mathrm{h}=\mathrm{kilometers}$ per hour, $\mathrm{RE}=$ running economy, $\mathrm{HR}=$ heart rate, and $\mathrm{bpm}=$ beats per a minute.

significantly lower in both the similar- $\mathrm{VO}_{2 \max }$ and different$\mathrm{VO}_{2 \max }$ (Figures 2(b) and 2(d)), while the glucose response to an OGTT did not differ (Figures 2(a) and 2(c)). Together these data indicate that in subjects matched for CRF high levels of PA are necessary for improved metabolic risk factors.

\subsection{Runners Markers of Performance Are Better Than Healthy} Controls Despite Similar-VO $\mathrm{O}_{2 \max } . \mathrm{VO}_{2 \max }$ is not necessarily a predictor of performance so we examined additional markers of exercise performance to see whether runners perform better regardless of their $\mathrm{VO}_{2 \max }$. The velocity at $\mathrm{VO}_{2 \max }$ and speed at lactate threshold was higher in the runners from both the similar- $-\mathrm{VO}_{2 \max }$ and different- $\mathrm{VO}_{2 \max }$ groups (Table 2). What may account for the higher velocity at $\mathrm{VO}_{2 \max }$, but not absolute $\mathrm{VO}_{2 \max }$ in the runners from the similar- $\mathrm{VO}_{2 \max }$ group was a difference in running economy. The similar$\mathrm{VO}_{2 \max }$ group, but not the different- $\mathrm{VO}_{2 \max }$, uses less relative oxygen at a given speed compared to their matched sedentary control group.
3.5. Runners Skeletal Muscle Has Higher Antioxidant and Oxidative Enzyme Content Relative to Healthy Controls. In addition to systemic measures of exercise capacity such as $\mathrm{VO}_{2 \max }$, velocity and $\mathrm{VO}_{2 \max }$, and lactate threshold we wanted to examine whether skeletal muscle markers for antioxidant and mitochondrial content were higher regardless of $\mathrm{VO}_{2 \max }$ in vastus lateralis skeletal muscle biopsies of runners (Figure 3 ). The skeletal muscle of marathon runners had significantly higher protein content of the antioxidant enzymes glutathione peroxidase 1 (GPX1) and mitochondrial superoxide dismutase (mnSOD), but not heat shock protein 72 (HSP70) (Figure 3). The difference in GPX1 (Figure 3(a)) was higher in runners from both the similar$\mathrm{VO}_{2 \max }$ and different- $\mathrm{VO}_{2 \max }$ group. Similarly, cytochrome oxidase subunit 4 (COXIV), a mitochondrial enzyme in electron transport chain, was higher in skeletal muscle from the runners in both the similar- $\mathrm{VO}_{2 \max }$ and different $-\mathrm{VO}_{2 \max }$ group (Figure 3(f)). However, runners and sedentary subjects had no differences in protein content glucose transporter 4 


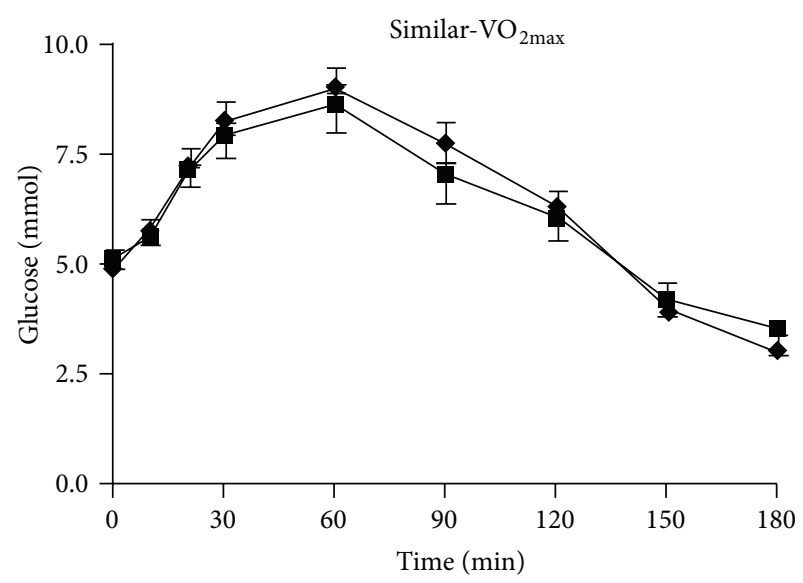

(a)

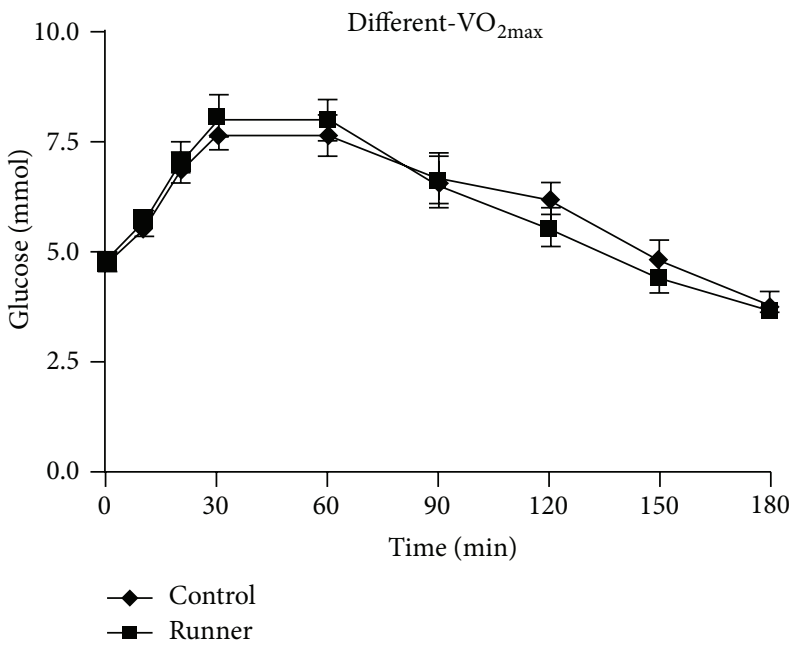

(c)

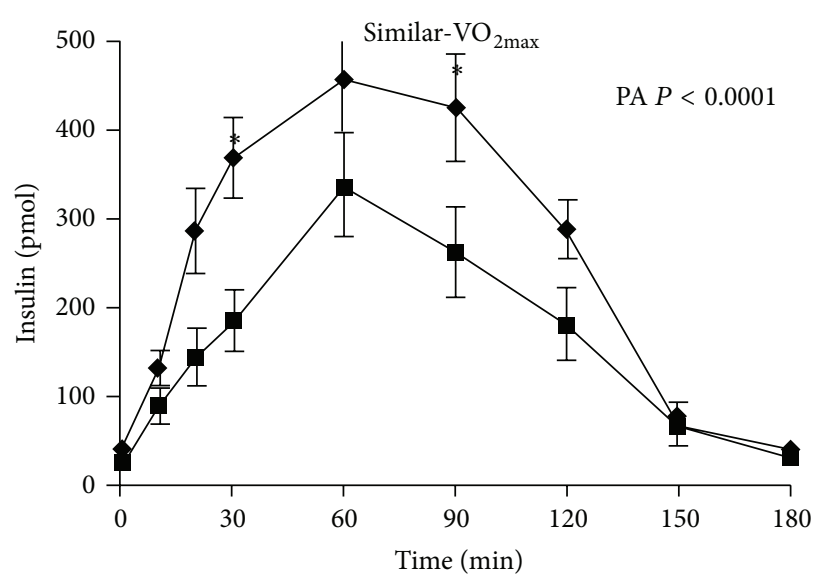

(b)

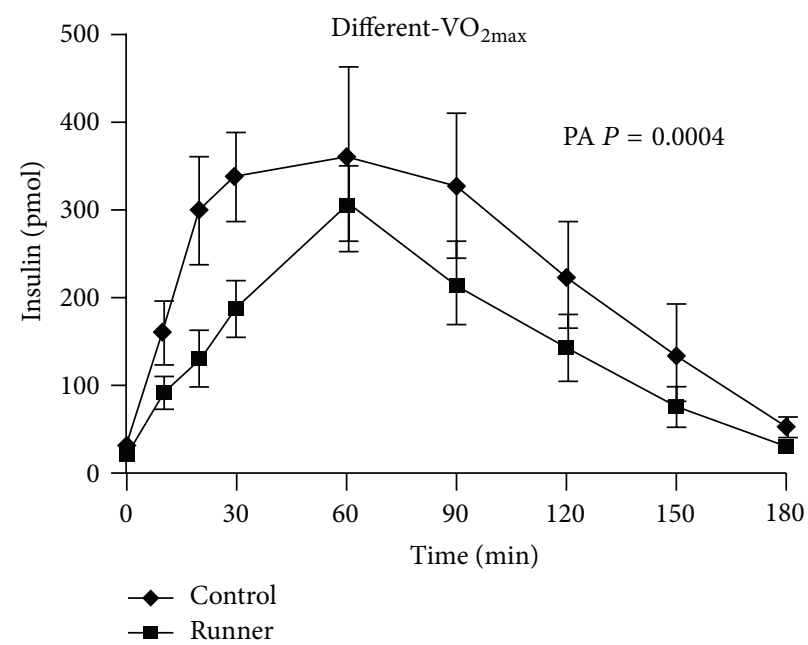

(d)

FIGURE 2: Oral glucose tolerance tests were conducted on marathon runners and sedentary paired controls with similar-VO $\mathrm{V}_{2 \max }((\mathrm{a}, \mathrm{b}), n=$ $10)$ and with different- $\mathrm{VO}_{2 \max }((\mathrm{c}, \mathrm{d}), n=10)$. While no differences in plasma glucose were seen between runners and sedentary controls regardless of $\mathrm{VO}_{2 \max }$ stratification, runners regardless of $\mathrm{VO}_{2 \max }$ stratification had a significantly lower insulin response $(P<0.0005$ for both groups, One-Way Repeated Measures ANOVA).

(Figure 3(g)), myosin heavy chain isoform IIa (Figure 3(d)), or vascular endothelial growth factor (Figure 3(e)). Thus, high levels of PA, rather than whole body $\mathrm{VO}_{2 \max }$, are associated with higher levels of specific markers of antioxidant capacity and mitochondrial content in skeletal muscle.

\section{Discussion}

The present case-control study clearly shows that a high amount of physical activity (PA) is associated with benefits on metabolic health parameters independent of cardiorespiratory fitness (CRF). Conversely a higher level of CRF without high levels of PA was associated with lower levels of metabolic fitness. Our measures of metabolic fitness included improved blood lipid profile, lower insulin response to an OGTT, and increased skeletal muscle mitochondrial markers. Furthermore, runners within the similar- $\mathrm{VO}_{2 \max }$ had superior exercise performance as measured by velocity at $\mathrm{VO}_{2 \max }$, lactate threshold, and submaximal running economy.
It is well accepted that PA and CRF reduce the risk of cardiovascular disease, diabetes, and all-cause mortality [2931]. However, the relative contributions of PA and CRF to the reduction in risk are less well known and few studies have been designed to pre hoc separate the effects of PA and CRF from each other. Still analyses of larger cohorts have in cross-sectional and longitudinal studies attempted to separate the effects of CRF and PA on health. For instance, with regard to mortality, the associations of PA and CRF were examined separately and in combination in a cohort of relatively healthy 20-82-year-old men and women [32]. Subjects with high levels CRF had lower mortality, while no association between PA and mortality was found. Conversely, data from another study showed higher levels of both PA and CRF associated with reduced risk factors for cardiovascular disease in a cohort of randomly selected 20-65-year-old Swedish men and women [33]. Furthermore, in attempt to separate the effects of CRF and PA, the author's analysis showed that subjects with a low CRF, but who were physically 
GPX1
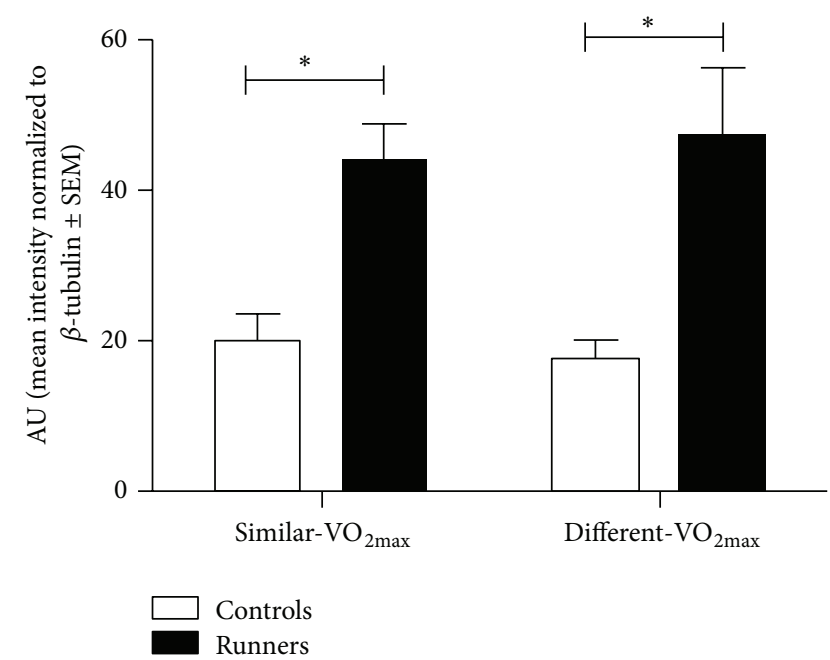

(a)

COXIV3E11
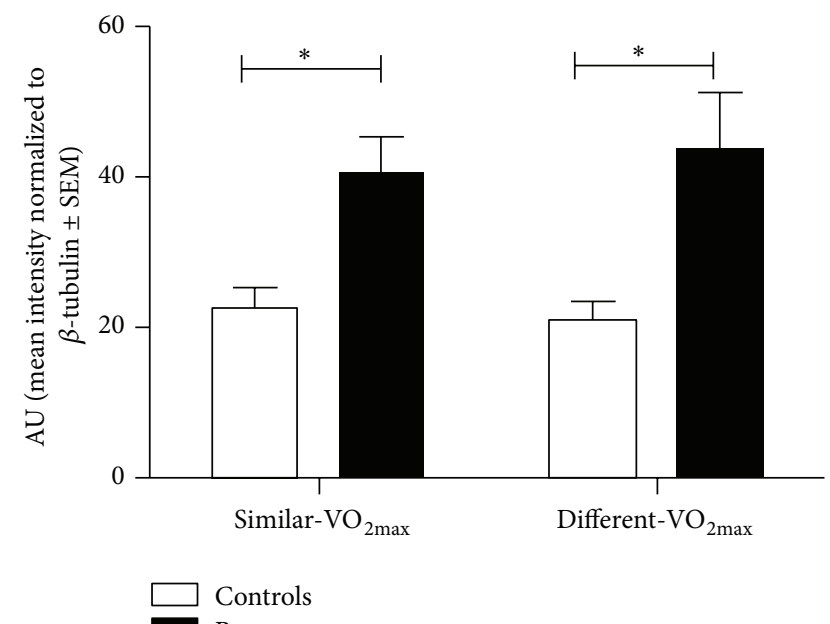

Runners

(c)

VEGF

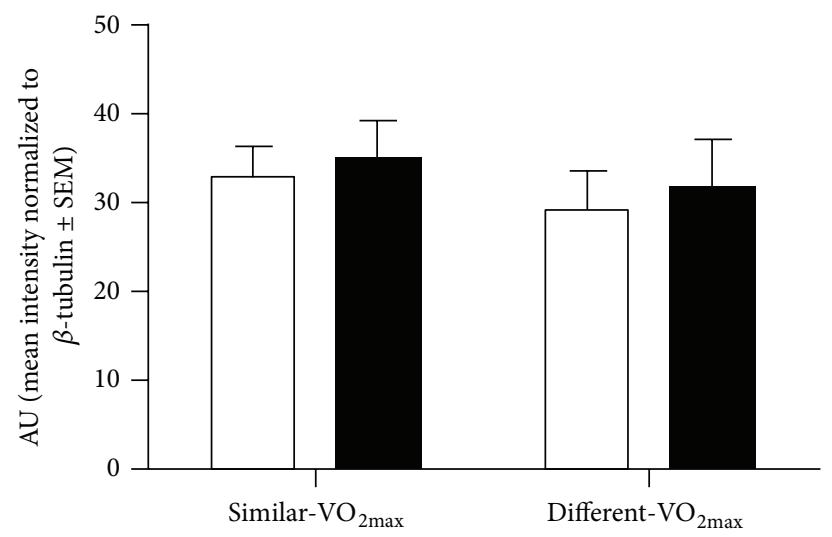

Controls

Runners

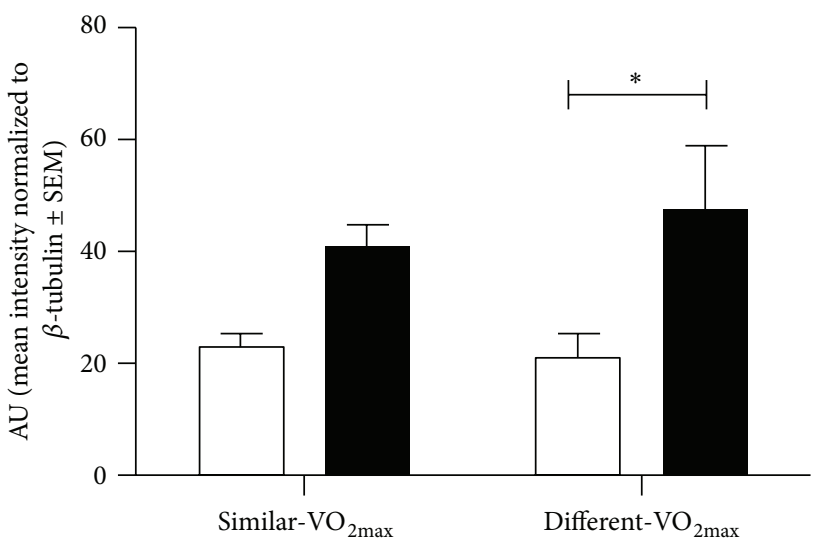

$\square$ Controls

Runners

(b)

MHCIIa

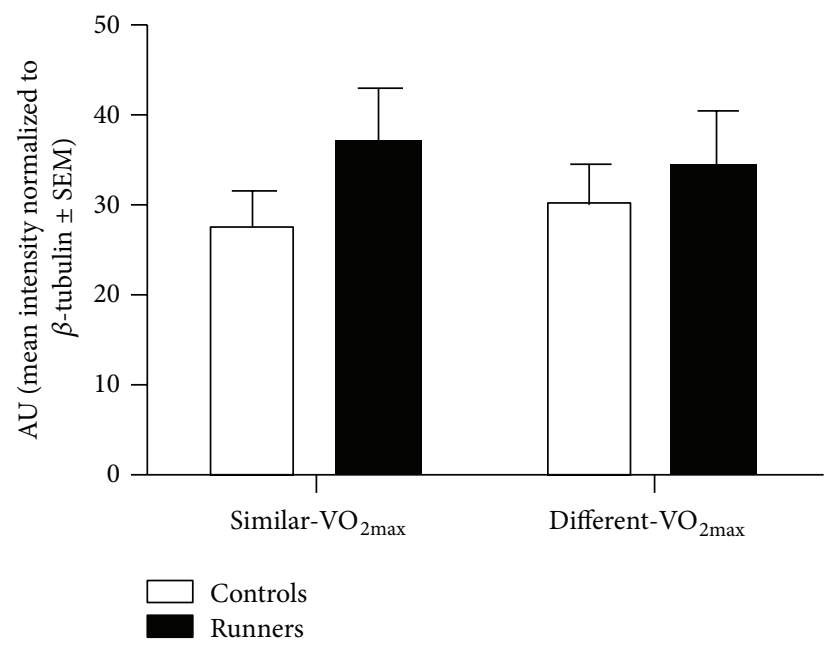

(d)

HSP70

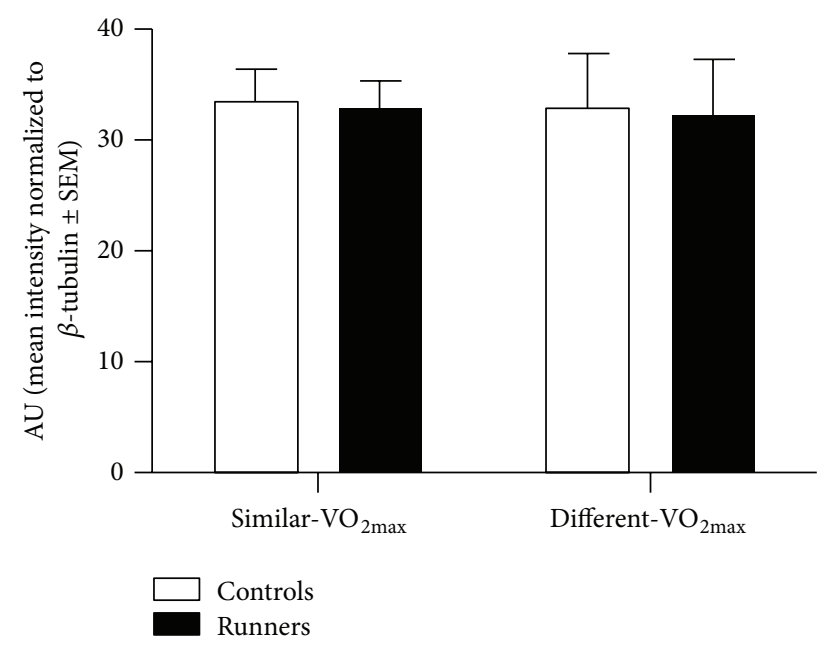

(e)

Figure 3: Continued. 


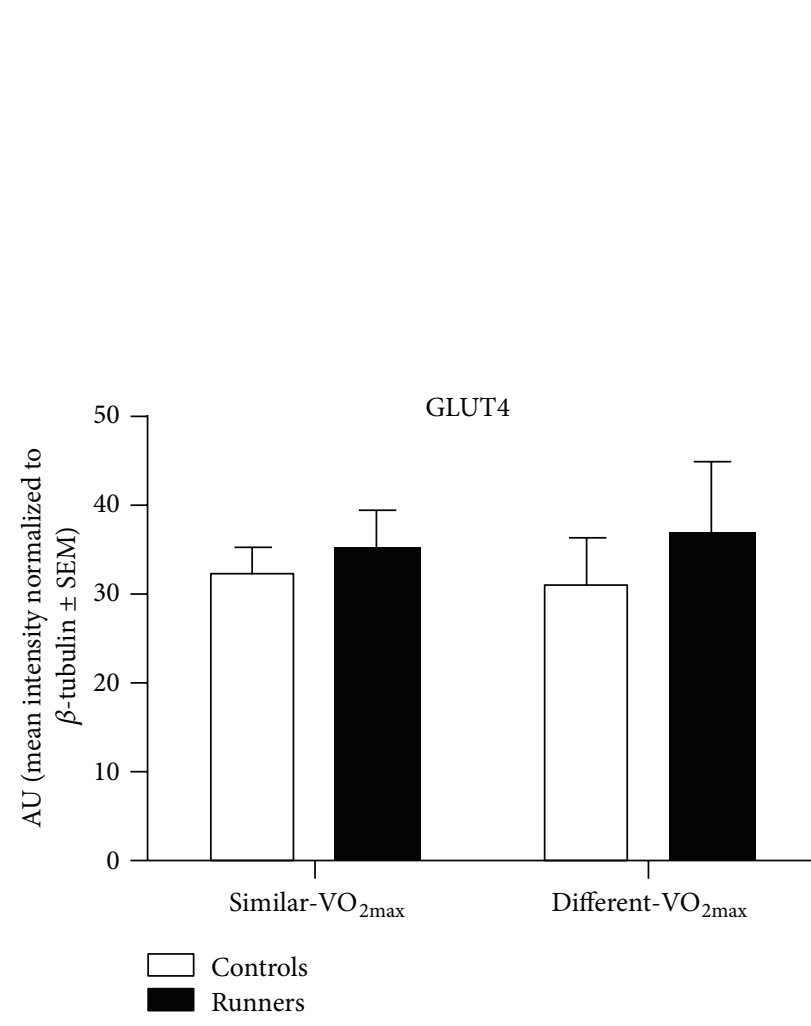

(g)

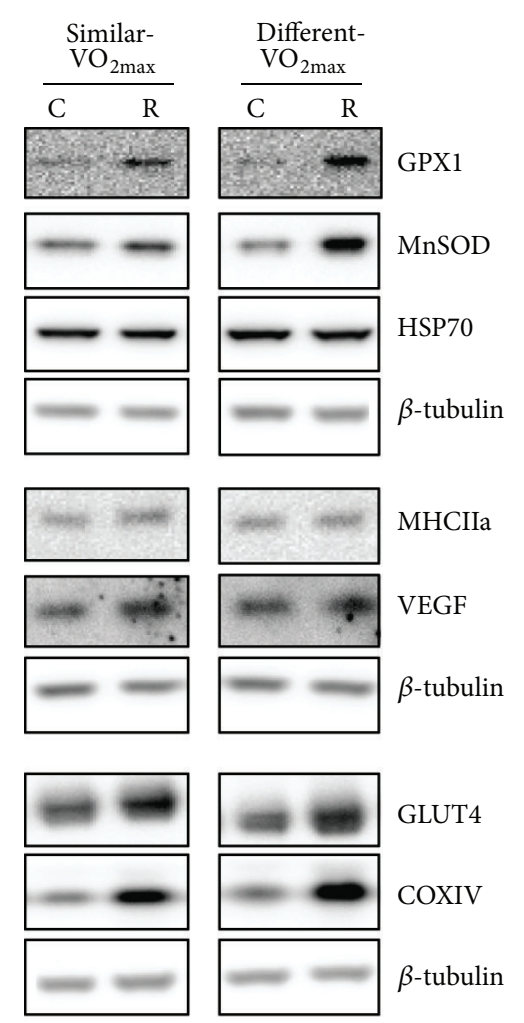

(h)

FIGURE 3: Protein levels as measured by western blot of traditional training markers in runners (solid bars) or pair sedentary controls (open bars) in resting vastus lateralis biopsies. Glutathione peroxidase 1 (a) and manganese superoxide dismutase (MnSOD) (b) were significantly higher in runners $(n=10, P<0.001,2$-way ANOVA). Mitochondrial complex IV (COXIV) (c) was significantly higher in runners $(n=10$, $P<0.001,2$-way ANOVA). Post hoc significance as determined by Bonferroni corrected $t$-test is indicated by a ${ }^{*}(P<0.05)$. Myosin heavy chain IIa (d), vascular endothelial growth factor (VEGF) (e), heat shock protein 70 (HSP70) (f), nor glucose transporter 4 (GLUT4) (g) did not differ between groups. Proteins of interest are normalized to $\beta$-tubulin as a loading control that did not differ between groups. Representative blots are shown in (h), with $\mathrm{C}$ indicating control and $\mathrm{R}$ indicating runner.

activity, had a $50 \%$ reduction in risk factors. However, the design of the study only groups subjects as only fit/unfit active/nonactive, which is a less robust method to match groups as we employed in the current study. While useful for large cohorts the dichotomization of groups by fit/unfit and active/nonactive may not best represent the complex interaction between CRF and PA.

The finding that the highly PA marathon runners had a more beneficial lipid profile than controls, independent of CRF, is in accordance with previous findings in "at risk groups" [34]. In a classic randomized-controlled trial by Kraus et al. [20] they determined the effect of the amount and intensity of training in 111 sedentary, overweight men and women with mild-to-moderate dyslipidemia. The study design randomly assigned subjects to a control group (no exercise training) or to 8 months of physical training entailing either high-amount-high-intensity exercise $(32 \mathrm{~km}$ jogging/week at $65-80 \%$ of peak oxygen uptake $\left.\left(\mathrm{VO}_{2 \max }\right)\right)$, lowamount-high-intensity exercise $(19 \mathrm{~km}$ jogging/week at $65-$ $80 \%$ percent of $\mathrm{VO}_{2 \max }$ ), or low-amount-moderate-intensity exercise (19 km walking/week at $40-55 \%$ of $\mathrm{VO}_{2 \max }$ ). Regardless of which exercise group they were assigned to all subjects showed improved lipoprotein profile (lower triglycerides, lower vLDL, and lower vLDL particle size) relative to the control group. However, which exercise group subjects were assigned to did make a difference in whether they improved CRF. The group that performed low-amount-high-intensity exercise improved CRF more than the low-amount-lowintensity group. Thus, both groups improved lipid profiles to a similar degree but improved CRF to a different level. In healthy subjects a change in PA without a change in CRF can lead to improved metabolic fitness. For instance, subjects who skied an average of $342 \mathrm{~min} /$ day on a 32 day cross country skiing trip across Greenland had a decrease in maximal CRF but still had an improvement in circulating lipoproteins [35]. While both of these studies were interventions lasting less than 9 months, we were interested in whether a similar finding would occur in long-term runners versus long-term sedentary subjects. Indeed we found that sedentary and runners with similar levels of CRF had different lipoprotein and insulin responses to an OGTT test. One potential explanation for this separation in CRF and metabolic health is the type of exercise the marathon runners do. Many of the subjects perform only low-intensity long duration types of exercise. 
This is in agreement with Houmard et al. [36] who showed that insulin sensitivity was improved more by an exercise training programme with high volume than high intensity. Insulin sensitivity is highly dependent on skeletal muscle specific adaptations, which may differ in response to PA or exercise training that increases CRF.

Some types of PA, such as low intensity or limited to small amount of tissue, may lead to significant local changes important for metabolic health without improved whole body CRF. Adaptation specific to the working muscle is illustrated in a number of studies on one-legged exercise training, which utilize a small fraction of whole body muscle mass result in important local adaptations in trained muscle such as increased capillarization, muscle glycogen content, mitochondrial activity, insulin sensitivity, and transcription of metabolic genes [37-40]. Vollaard et al. [41] find these local changes in muscle metabolism are associated with changes in maximal work capacity more so than $\mathrm{VO}_{2 \max }$. Furthermore, an increase in $\mathrm{VO}_{2 \max }$ with a $\mathrm{PA}$ intervention is not even necessary to improve muscle mitochondrial content. For instance, despite not improving CRF cross country, skiers sill improved skeletal muscle mitochondrial [35]. Similarly, in our study it was the high levels of PA, and not a high CRF, that was associated with higher protein levels of the mitochondrial protein COXIV and antioxidant enzyme mnSOD. The exact physiological, genetic, and environmental contributions that determine individuals $\mathrm{VO}_{2 \max }$ vary tremendously and are not completely known.

We were surprised that so many (one-third) of the marathon runners did not have substantially higher $\mathrm{VO}_{2 \max }$ than their sedentary match subject. A number of twin studies (reviewed in [1]) have determined a typical genetic contribution for the baseline physical fitness characteristics and responses to standardized aerobic and strength training programs of approximately $50 \%$. The largest single study examining genetic and exercise training interactions with health outcomes is the HERITAGE Family Study [16], which suggested significant genetic variation in the interaction between $\mathrm{VO}_{2 \max }$ and risk factors such as resting systolic blood pressure, fasting plasma HDL-cholesterol, triglycerides, and insulin. The HERITAGE study showed that between $8 \%$ and $13 \%$ of exercise intervention participants have worse off risk factors following 20 weeks to 6 months of exercise training programs [42]. Some specific genes that may contribute to these differences in response to exercise have been identified already. An ongoing study listed in 2005 that 165 autosomal gene entries were found to alter physical performance and health parameters, some of which are only present in response to PA, such as variants in AKT [43], perilipin [44], and FTO [45]. However, the HERITAGE study did not examine what proportion of the inactive groups developed worse risk factors. Other studies which include an inactive control group show worsening of 12 different risk factors including 3 of the 4 examined above (blood pressure was not measured) following 6 months of inactivity [46]. Our current cross-sectional study design only allows us to make association and future studies that trained subjects over a period of time or followed the same subjects over a number of years could provide information about the relative contribution of environment and genetics.

We believe our study has distinctions over previous studies. First is that we selected runners that have been running for at least 5 years in a fairly consistent manner, either completing two marathons per a year or having averaged more than $50 \mathrm{~km} /$ week over the past 5 years. This is substantially more exercise for a much longer duration than the large clinical intervention studies such as the HERITAGE and STRRIDE studies $[15,46]$. Second, we recruited everyday athletes rather than elites, which have been studied at older ages previously. For instance, Trappe et al. [47] examined the performance abilities of elite octotarian lifelong athletes versus healthy untrained men. Octotarian athletes had $\mathrm{VO}_{2 \max }$ and max workloads that were $80 \%$ and $51 \%$ higher than a matched sedentary group. While our subjects spanned a much larger age range the subjects most runners had significantly higher $\mathrm{VO}_{2 \max }$ and max workload (running speed). Excluding the runners in the similar- $\mathrm{VO}_{2 \max }$ group $\left(r^{2}=0.04\right) \mathrm{VO}_{2 \max }$ and max workload were highly correlated $\left(r^{2}=0.48-0.80\right)$, a relationship that is also present in octotarian athletes and sedentary controls. In general the runners in the similar$\mathrm{VO}_{2 \max }$ group had higher max workloads than their $\mathrm{VO}_{2 \max }$ would predict. This discrepancy between max workload and $\mathrm{VO}_{2 \max }$ is likely due to the superior running economy it the similar- $\mathrm{VO}_{2 \max }$ group compared to their sedentary controls. Together the data suggests that multiple types of physiological adaptations may occur to result in an improved work capacity following years of high levels of PA.

There are a number of limitations in the present study that are worth discussing. First, although within our similar$\mathrm{VO}_{2 \max }$ group there was no statistical difference between the runners and the sedentary group there was a 5\% relative $(2.2 \mathrm{~mL} / \mathrm{kg} / \mathrm{min}$ absolute $)$ higher- $\mathrm{VO}_{2 \max }$ that may have contributed to some of the metabolic benefits seen in the runners. However, runners in both the similar- $\mathrm{VO}_{2 \max }$ and different $-\mathrm{VO}_{2 \max }$ had similar improvements in metabolic fitness, arguing against the relative difference in $\mathrm{VO}_{2 \max }$ being important for metabolic health. Second, a larger subject population number would have allowed for more advanced statistical analysis that could model the variables as continuous and more precisely determine the relative contribution of $\mathrm{VO}_{2 \max }$ to different metabolic phenotypes. However, given our difficult inclusion criteria for the runner group and difficulty in finding BMI and age matched sedentary controls, it would still remain difficult to recruit hundreds of subjects. Similarly because the training that the runners did was not controlled there are likely a number of individual differences within the runner group that may contribute positively or negatively to the findings seen. Finally, while we observed improved metabolic health of the runners in our group, the metabolic health of the sedentary group remained within clinically normal ranges. However, even within the normal range of clinical variables, small variations in lipoproteins $[48,49]$ and blood pressure [50] are associated with varied outcomes and risks for cardiovascular disease and death.

In summary the present cross-sectional case-control study suggests that a high amount of PA independent of CRF 
is associated with positive benefits on a number of metabolic health parameters as well as markers of performance.

\section{Conflict of Interests}

No conflict of interests is reported.

\section{Acknowledgments}

The Centre of Inflammation and Metabolism (CIM) is supported by a grant from the Danish National Research Foundation (no. 02-512-55) and is part of the UNIK Project: Food, Fitness \& Pharma for Health and Disease, supported by the Danish Ministry of Science, Technology, and Innovation. M. J. Laye was supported by a postdoctoral grant from the Danish Ministry of Science, Technology, and Innovation and additional support was provided by Augustinus Fonden. The authors wish to thank Miss Hanne Villumsen and Miss Ruth Rovsing for their technical support and assistance. They also thank the subjects for taking part in their study. M. J. Laye and B. K. Pedersen formulated the study design and wrote the paper. M. J. Laye takes responsibility for the integrity of the data. M. B. Nielsen, L. S. Hansen, and T. Knudsen conducted the clinical studies. M. J. Laye planned the analyses and performed laboratory assays and analyzed the data. All authors were involved in editing and approval of the final version of the paper.

\section{References}

[1] F. W. Booth, C. K. Roberts, and M. J. Laye, "Lack of exercise is a major cause of chronic diseases," Comprehensive Physiology, vol. 2, no. 2, pp. 1143-1211, 2012.

[2] R. D. Telford, "Low physical activity and obesity: causes of chronic disease or simply predictors?" Medicine and Science in Sports and Exercise, vol. 39, no. 8, pp. 1233-1240, 2007.

[3] M. Fogelholm, "Physical activity, fitness and fatness: relations to mortality, morbidity and disease risk factors. A systematic review," Obesity Reviews, vol. 11, no. 3, pp. 202-221, 2010.

[4] D. C. Lee, X. Sui, and S. N. Blair, "Does physical activity ameliorate the health hazards of obesity?" British Journal of Sports Medicine, vol. 43, no. 1, pp. 49-51, 2009.

[5] J. W. R. Twisk, H. C. G. Kemper, and W. Van Mechelen, “The relationship between physical fitness and physical activity during adolescence and cardiovascular disease risk factors at adult age. The Amsterdam Growth and Health Longitudinal Study," International Journal of Sports Medicine, vol. 23, supplement 1, pp. S8-S14, 2002.

[6] S. N. Blair, Y. Cheng, and J. Scott Holder, "Is physical activity or physical fitness more important in defining health benefits?" Medicine and Science in Sports and Exercise, vol. 33, no. 6, pp. S379-S399, 2001.

[7] P. Ferrari, C. Friedenreich, and C. E. Matthews, "The role of measurement error in estimating levels of physical activity," American Journal of Epidemiology, vol. 166, no. 7, pp. 832-840, 2007.

[8] P. H. Lee, D. J. Macfarlane, T. H. Lam, and S. M. Stewart, "Validity of the international physical activity questionnaire short form (IPAQ-SF): a systematic review," International Journal of Behavioral Nutrition and Physical Activity, vol. 8, article 115, 2011.
[9] J. Myers, M. Prakash, V. Froelicher, D. Do, S. Partington, and J. Edwin Atwood, "Exercise capacity and mortality among men referred for exercise testing," The New England Journal of Medicine, vol. 346, no. 11, pp. 793-801, 2002.

[10] S. N. Blair, H. W. Kohl III, R. S. Paffenbarger Jr., D. G. Clark, K. H. Cooper, and L. W. Gibbons, "Physical fitness and all-cause mortality: a prospective study of healthy men and women," The Journal of the American Medical Association, vol. 262, no. 17, pp. 2395-2401, 1989.

[11] C. Y. Wang, W. L. Haskell, S. W. Farrell et al., "Cardiorespiratory fitness levels among us adults 20-49 years of age: findings from the 1999-2004 national health and nutrition examination survey," The American Journal of Epidemiology, vol. 171, no. 4, pp. 426-435, 2010.

[12] W. M. Kohrt, M. T. Malley, A. R. Coggan et al., "Effects of gender, age, and fitness level on response of VO2max to training in 6071 yr olds," Journal of Applied Physiology, vol. 71, no. 5, pp. 20042011, 1991.

[13] J. H. Wilmore, J. S. Green, P. R. Stanforth et al., "Relationship of changes in maximal and submaximal aerobic fitness to changes in cardiovascular disease and non-insulin-dependent diabetes mellitus risk factors with endurance training: the Heritage Family Study," Metabolism: Clinical and Experimental, vol. 50, no. 11, pp. 1255-1263, 2001.

[14] R. Fagard, E. Bielen, and A. Amery, "Heritability of aerobic power and anaerobic energy generation during exercise," Journal of Applied Physiology, vol. 70, no. 1, pp. 357-362, 1991.

[15] C. Bouchard, P. An, T. Rice et al., "Familial aggregation of $\mathrm{VO}(2 \mathrm{max})$ response to exercise training: results from the HERITAGE family study," Journal of Applied Physiology, vol. 87, no. 3, pp. 1003-1008, 1999.

[16] C. Bouchard and T. Rankinen, "Individual differences in response to regular physical activity," Medicine \& Science in Sports \& Exercise, vol. 33, no. 6, supplement, pp. S443-S452, 2001.

[17] A. J. Hautala, T. H. Mäkikallio, A. Kiviniemi et al., "Cardiovascular autonomic function correlates with the response to aerobic training in healthy sedentary subjects," The American Journal of Physiology-Heart and Circulatory Physiology, vol. 285, no. 4, pp. H1747-H1752, 2003.

[18] K. O. Bennett, C. J. Billings, M. R. Molis, and M. R. Leek, "Neural encoding and perception of speech signals in informational masking," Ear and Hearing, vol. 33, no. 2, pp. 231-238, 2012.

[19] J. M. R. Gill and D. Malkova, "Physical activity, fitness and cardiovascular disease risk in adults: interactions with insulin resistance and obesity," Clinical Science, vol. 110, no. 4, pp. 409425, 2006.

[20] W. E. Kraus, J. A. Houmard, B. D. Duscha et al., "Effects of the amount and intensity of exercise on plasma lipoproteins," The New England Journal of Medicine, vol. 347, no. 19, pp. 1483-1492, 2002.

[21] J. M. R. Gill and A. E. Hardman, "Exercise and postprandial lipid metabolism: an update on potential mechanisms and interactions with high-carbohydrate diets (review)," Journal of Nutritional Biochemistry, vol. 14, no. 3, pp. 122-132, 2003.

[22] A. M. W. Petersen and B. K. Pedersen, "The anti-inflammatory effect of exercise," Journal of Applied Physiology, vol. 98, no. 4, pp. 1154-1162, 2005.

[23] A. Maiorana, G. O'Driscoll, C. Cheetham et al., "The effect of combined aerobic and resistance exercise training on vascular function in type 2 diabetes," Journal of the American College of Cardiology, vol. 38, no. 3, pp. 860-866, 2001. 
[24] N. Owen, G. N. Healy, C. E. Matthews, and D. W. Dunstan, "Too much sitting: the population health science of sedentary behavior," Exercise and Sport Sciences Reviews, vol. 38, no. 3, pp. 105-113, 2010.

[25] B. Saltin, G. Blomqvist, J. H. Mitchell, R. L. Johnson Jr., K. Wildenthal, and C. B. Chapman, "Response to exercise after bed rest and after training," Circulation, vol. 38, no. 5, pp. 71$78,1968$.

[26] R. H. Olsen, R. Krogh-Madsen, C. Thomsen, F. W. Booth, and B. K. Pedersen, "Metabolic responses to reduced daily steps in healthy nonexercising men," The Journal of the American Medical Association, vol. 299, no. 11, pp. 1261-1263, 2008.

[27] C. J. Green, M. Pedersen, B. K. Pedersen, and C. Scheele, "Elevated NF- $\kappa$ B activation is conserved in human myocytes cultured from obese type 2 diabetic patients and attenuated by AMP-activated protein kinase," Diabetes, vol. 60, no. 11, pp. 2810-2819, 2011.

[28] M. M. Bradford, "A rapid and sensitive method for the quantitation of microgram quantities of protein utilizing the principle of protein dye binding," Analytical Biochemistry, vol. 72, no. 1-2, pp. 248-254, 1976.

[29] F. J. Apullan, M. G. Bourassa, J.-C. Tardif, A. Fortier, M. Gayda, and A. Nigam, "Usefulness of self-reported leisure-time physical activity to predict long-term survival in patients with coronary heart disease," The American Journal of Cardiology, vol. 102 , no. 4, pp. 375-379, 2008.

[30] A. Rosengren and L. Wilhelmsen, "Physical activity protects against coronary death and deaths from all causes in middleaged men. Evidence from a 20-year follow-up of the primary prevention study in Goteborg," Annals of Epidemiology, vol. 7, no. 1, pp. 69-75, 1997.

[31] K.-T. Khaw, R. Jakes, S. Bingham et al., "Work and leisure time physical activity assessed using a simple, pragmatic, validated questionnaire and incident cardiovascular disease and allcause mortality in men and women: the European Prospective Investigation into Cancer in Norfolk prospective population study," International Journal of Epidemiology, vol. 35, no. 4, pp. 1034-1043, 2006

[32] S. D. Stovitz, "Contributions of fitness and physical activity to reducing mortality," Clinical Journal of Sport Medicine, vol. 22, no. 4, pp. 380-381, 2012.

[33] E. Ekblom-Bak, M.-L. Hellénius, Ö. Ekblom, L.-M. Engström, and B. Ekblom, "Independent associations of physical activity and cardiovascular fitness with cardiovascular risk in adults", European Journal of Cardiovascular Prevention and Rehabilitation, vol. 17, no. 2, pp. 175-180, 2010.

[34] B. K. Pedersen and B. Saltin, "Evidence for prescribing exercise as therapy in chronic disease," Scandinavian Journal of Medicine and Science in Sports, vol. 16, no. 1, pp. 3-63, 2006.

[35] J. W. Helge, R. Damsgaard, K. Overgaard et al., "Low-intensity training dissociates metabolic from aerobic fitness," Scandinavian Journal of Medicine and Science in Sports, vol. 18, no. 1, pp. 86-94, 2008.

[36] J. A. Houmard, C. J. Tanner, C. A. Slentz, B. D. Duscha, J. S. McCartney, and W. E. Kraus, "Effect of the volume and intensity of exercise training on insulin sensitivity," Journal of Applied Physiology, vol. 96, no. 1, pp. 101-106, 2004.

[37] B. Kiens, B. Essen-Gustavsson, N. J. Christensen, and B. Saltin, "Skeletal muscle substrate utilization during submaximal exercise in man: effect of endurance training," Journal of Physiology, vol. 469 , pp. 459-478, 1993.
[38] H. Pilegaard, B. Saltin, and D. P. Neufer, "Exercise induces transient transcriptional activation of the PGC-1alpha gene in human skeletal muscle," Journal of Physiology, vol. 546, part 3, pp. 851-858, 2003.

[39] H. Pilegaard, G. A. Ordway, B. Saltin, and P. D. Neufer, “Transcriptional regulation of gene expression in human skeletal muscle during recovery from exercise," The American Journal of Physiology-Endocrinology and Metabolism, vol. 279, no. 4, pp. E806-E814, 2000.

[40] F. Dela, J. J. Larsen, K. J. Mikines, T. Ploug, L. N. Petersen, and H. Galbo, "Insulin-stimulated muscle glucose clearance in patients with NIDDM: effects of one-legged physical training," Diabetes, vol. 44, no. 9, pp. 1010-1020, 1995.

[41] N. B. J. Vollaard, D. Constantin-Teodosiu, K. Fredriksson et al., "Systematic analysis of adaptations in aerobic capacity and submaximal energy metabolism provides a unique insight into determinants of human aerobic performance," Journal of Applied Physiology, vol. 106, no. 5, pp. 1479-1486, 2009.

[42] C. Bouchard, S. N. Blair, T. S. Church et al., "Adverse metabolic response to regular exercise: is it a rare or common occurrence?" PLoS ONE, vol. 7, no. 5, Article ID e37887, 2012.

[43] J. A. Mckenzie, S. Witkowski, A. T. Ludlow, S. M. Roth, and J. M. Hagberg, "AKT1 G205T genotype influences obesity-related metabolic phenotypes and their responses to aerobic exercise training in older Caucasians," Experimental Physiology, vol. 96, no. 3, pp. 338-347, 2011.

[44] N. T. Jenkins, J. A. McKenzie, C. M. Damcott, S. Witkowski, and J. M. Hagberg, "Endurance exercise training effects on body fatness, VO2max HDL-C subfractions, and glucose tolerance are influenced by a PLIN haplotype in older Caucasians," Journal of Applied Physiology, vol. 108, no. 3, pp. 498-506, 2010.

[45] T. Rankinen, T. Rice, M. Teran-Garcia, D. C. Rao, and C. Bouchard, "FTO genotype is associated with exercise traininginduced changes in body composition," Obesity, vol. 18, no. 2, pp. 322-326, 2010.

[46] C. A. Slentz, J. A. Houmard, and W. E. Kraus, "Modest exercise prevents the progressive disease associated with physical inactivity," Exercise and Sport Sciences Reviews, vol. 35, no. 1, pp. 1823, 2007.

[47] S. Trappe, E. Hayes, A. Galpin et al., "New records in aerobic power among octogenarian lifelong endurance athletes," Journal of Applied Physiology, vol. 114, no. 1, pp. 3-10, 2013.

[48] S. Lewington, G. Whitlock, R. Clarke et al., "Blood cholesterol and vascular mortality by age, sex, and blood pressure: a metaanalysis of individual data from 61 prospective studies with 55, 000 vascular deaths," The Lancet, vol. 370, no. 9602, pp. 18291839,2007

[49] R. Huxley, S. Lewington, and R. Clarke, "Cholesterol, coronary heart disease and stroke: a review of published evidence from observational studies and randomized controlled trials," Seminars in vascular medicine, vol. 2, no. 3, pp. 315-323, 2002.

[50] S. Lewington, R. Clarke, N. Qizilbash, R. Peto, and R. Collins, "Age-specific relevance of usual blood pressure to vascular mortality: a meta-analysis of individual data for one million adults in 61 prospective studies," The Lancet, vol. 360, no. 9349, pp. 1903-1913, 2002. 


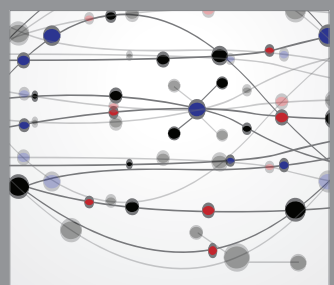

The Scientific World Journal
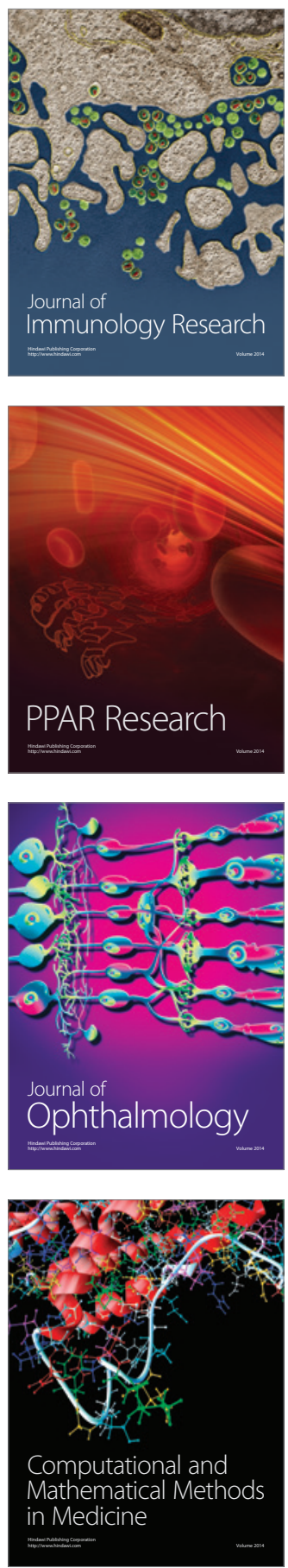

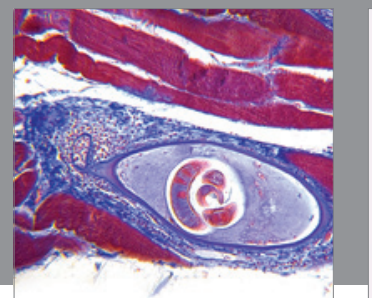

Gastroenterology

Research and Practice
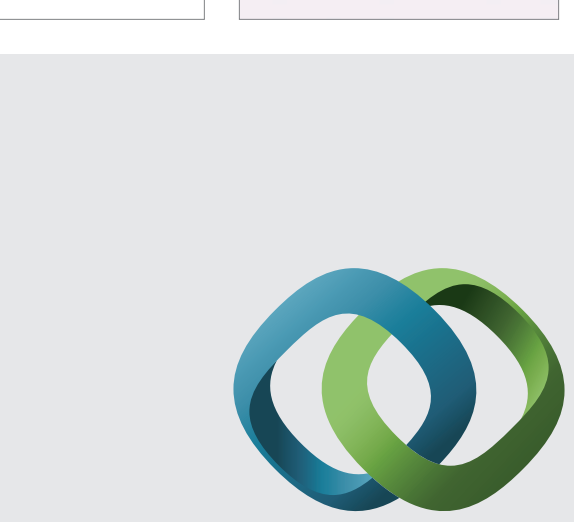

\section{Hindawi}

Submit your manuscripts at

http://www.hindawi.com
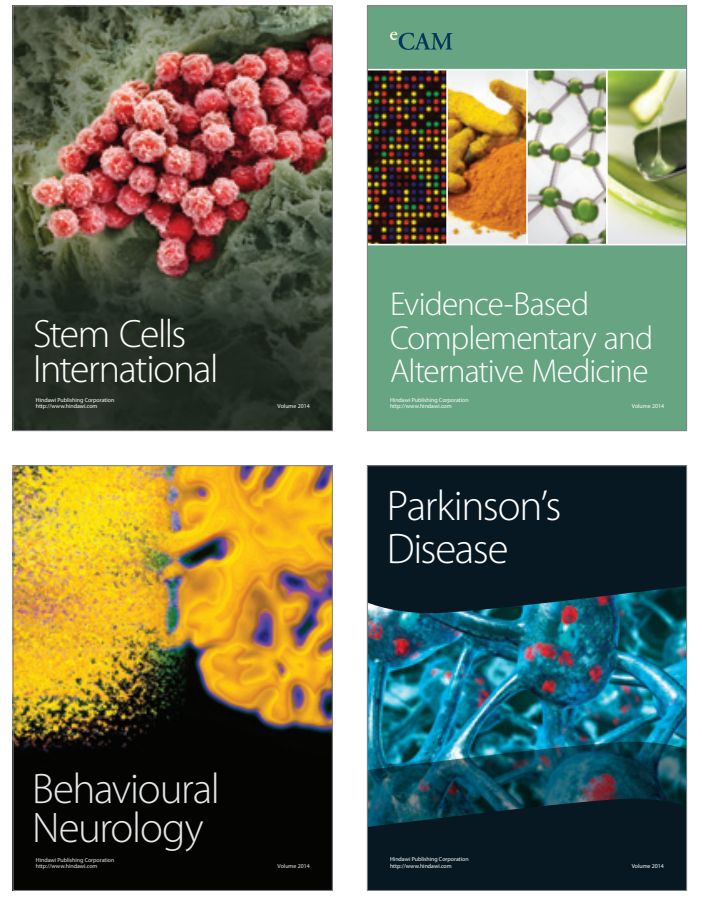
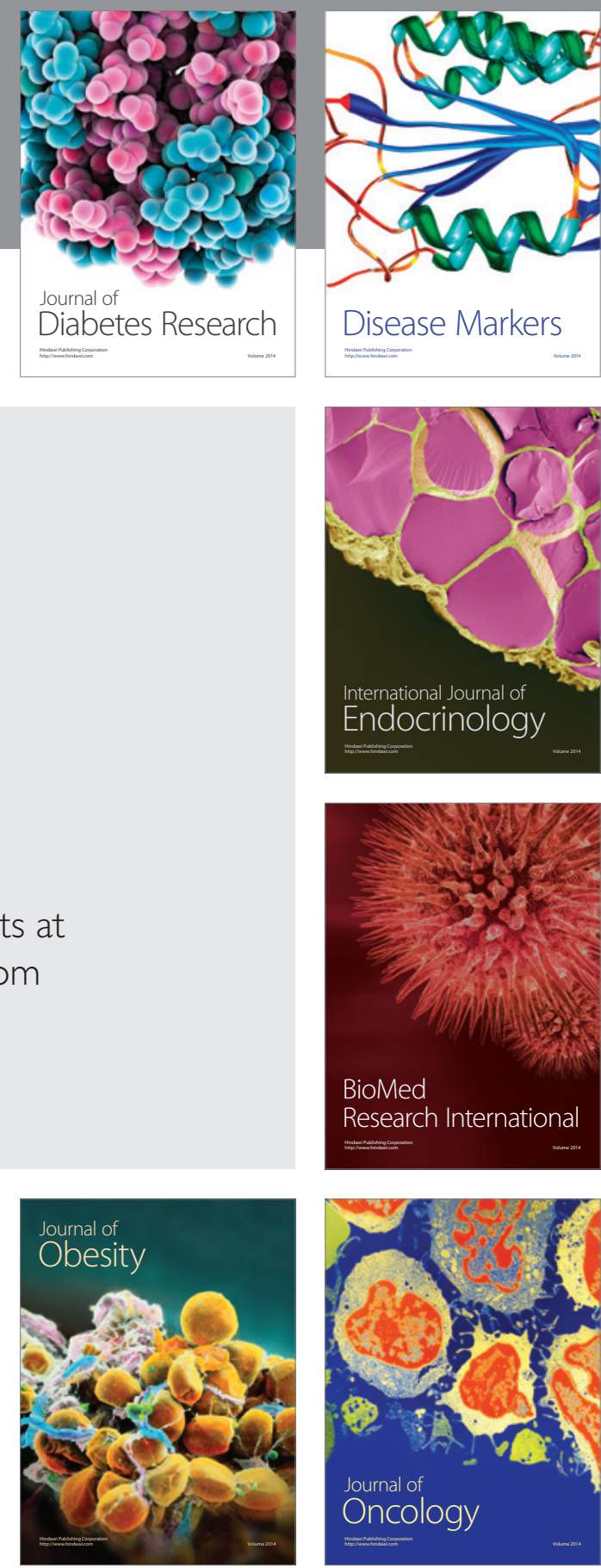

Disease Markers
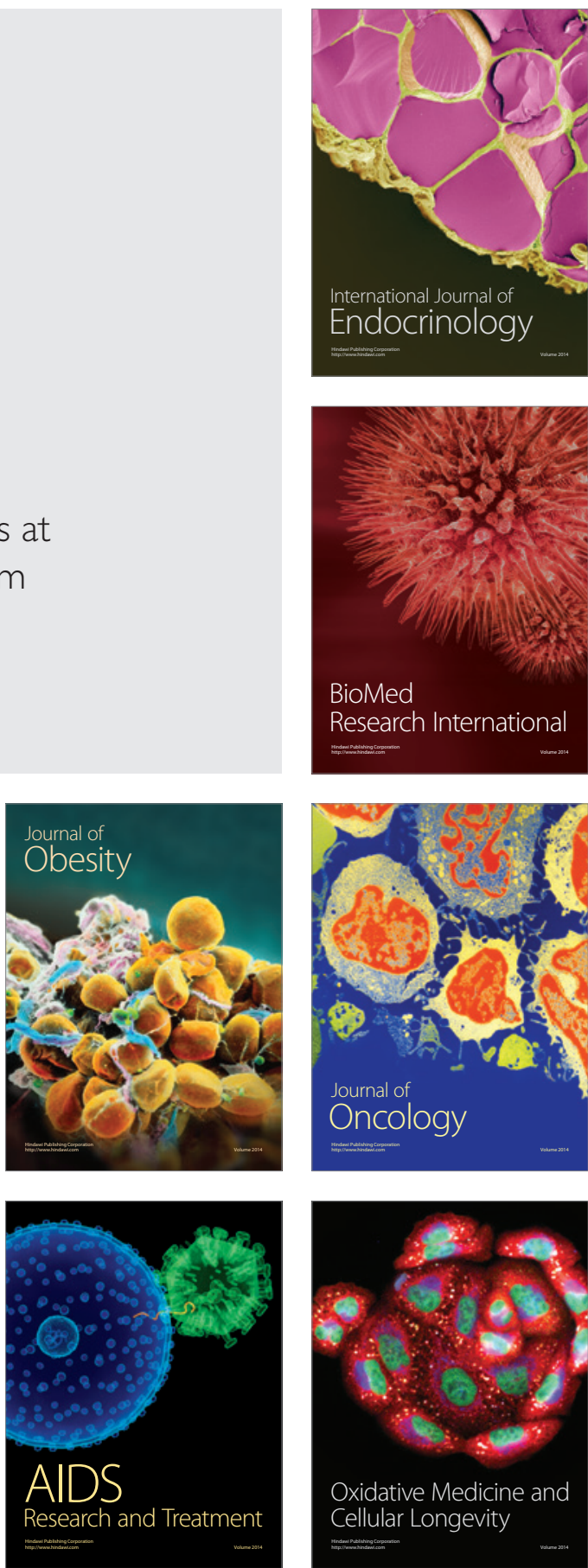